\title{
Redox Sensitivity of Tyrosine Hydroxylase Activity and Expression in Dopaminergic Dysfunction
}

\author{
Giuseppe Di Giovanni* ${ }^{*, 1,2}$, Mauro Pessia ${ }^{3}$ and Roberto Di Maio ${ }^{*, 4,5}$ \\ ${ }^{I}$ Department of Physiology \& Biochemistry, Faculty of Medicine and Surgery, University of Malta, Malta \\ ${ }^{2}$ School of Biosciences, Cardiff University, Cardiff, UK \\ ${ }^{3}$ Section of Human Physiology, University of Perugia School of Medicine, Perugia, Italy \\ ${ }^{4}$ Pittsburgh Institute for Neurodegenerative Diseases and Department of Neurology, University of Pittsburgh, \\ Pittsburgh, USA \\ ${ }^{5}$ RiMED Foundation, Palermo, Italy
}

\begin{abstract}
Oxidant molecules generated during neuronal metabolism appear to play a significant role in the processes of aging and neurodegeneration. Increasing experimental evidence suggests the noteworthy relevance of the intracellular reduction-oxidation (redox) balance for the dopaminergic (DA-ergic) neurons of the substantia nigra pars compacta. These cells possess a distinct physiology intrinsically associated with elevated reactive oxygen species production, conferring on them a high vulnerability to free radical damage, one of the major causes of selective DA-ergic neuron dysfunction and degeneration related to neurological disorders such as Parkinson's disease. Tyrosine hydroxylase (tyrosine 3-monooxygenase; E.C. 1.14.16.2; TH) activity represents the rate-limiting biochemical event in DA synthesis. TH activity, metabolism and expression are finely tuned by several regulatory systems in order to maintain a crucial physiological condition in which DA synthesis is closely coupled to its secretion. Alterations of these regulatory systems of TH functions have indeed been thought to be key events in the DA-ergic degeneration. TH has seven cysteine residues presenting thiols. Depending on the oxido-reductive (redox) status of the cellular environment, thiols exist either in the reduced form of free thiols or oxidized to disulfides. The formation of disulfides in proteins exerts critical regulatory functions both in physiological and in pathological conditions when oxidative stress is sustained. Several reports have recently shown that redox state changes of thiol residues, as consequence of an oxidative injury, can directly or indirectly affect the TH activity, metabolism and expression.

The major focus of this review, therefore, is to report recent evidence on the redox modulation of $\mathrm{TH}$ activity and expression, and to provide an overview of a cellular phenomenon that might represent a target for new therapeutic strategies against the DA-ergic neurodegenerative disorders.
\end{abstract}

Keywords: Dopamine, tyrosine hydroxylase, reactive oxygen species, Parkinson's disease, neurodegenaration.

\section{INTRODUCTION}

The major biochemical processes are characterized by fluxes of electrons between molecules: an oxidized donor and a reduced acceptor. Flux occurs spontaneously from more negative potential to less negative ones; thus, electrons travel in a preferential direction. As a direct consequence, the cellular environment has a natural tendency to oxidize. This physiological trend towards oxidation is counterbalanced and finely tuned by the enzymatic and non-enzymatic activity of antioxidant species to maintain the redox homeostasis. The redox balance relies mostly on the thiol groups of cysteine (Cys) residues. Thiol groups are particularly sensitive to variations in the redox environment, since they can be

*Address correspondence to this author at the Department of Physiology \& Biochemistry, Faculty of Medicine and Surgery, University of Malta. Msida MSD 2080, Malta; Tel: +356 23402776, +356 21316655; Fax: +356 21310577; E-mail: giuseppe.digiovanni@um.edu.mt and Pittsburgh Institute for Neurodegenerative Diseases and Department of Neurology, University of Pittsburgh, 3501 Fifth Avenue, Pittsburgh, PA 15260, USA;

Tel: 001-412-648-9154; Fax 001-412-648-7029;

E-mail: rdimaio@hs.pitt.edu readily oxidized to disulfides. This reversible electronexchange and non-enzymatic reaction constitutes an early response to buffer alterations in the redox homeostasis [1].

Reuced glutathione (GSH) and thioredoxins, two molecules specialized in the control of the redox state, constitute the major non-enzymatic/enzymatic cellular redox buffers. Moreover, other proteins or enzymes can participate in redox control, and constitute the protein thiol pool $[2,3]$. Besides contributing to redox regulation, oxidation of Cys in the protein thiol pool can have other important effects. Thiol redox changes, indeed, can be protective, preventing higher forms of oxidation, such as the formation of sulfenic acid, an irreversible, two-electron oxidation of Cys residues [1]. Irreversible oxidation of proteins can change their physical properties, promoting events such as aggregation, and can alter protein function, either providing new functions (gain of function) or reducing the normal one (loss of function) $[4$, 5].

If under any circumstance the redox balance is altered in favour of the pro-oxidant events, the state is defined as oxidative stress. The increase in the production of reactive oxygen species (ROS) will generate an abnormal flux of 


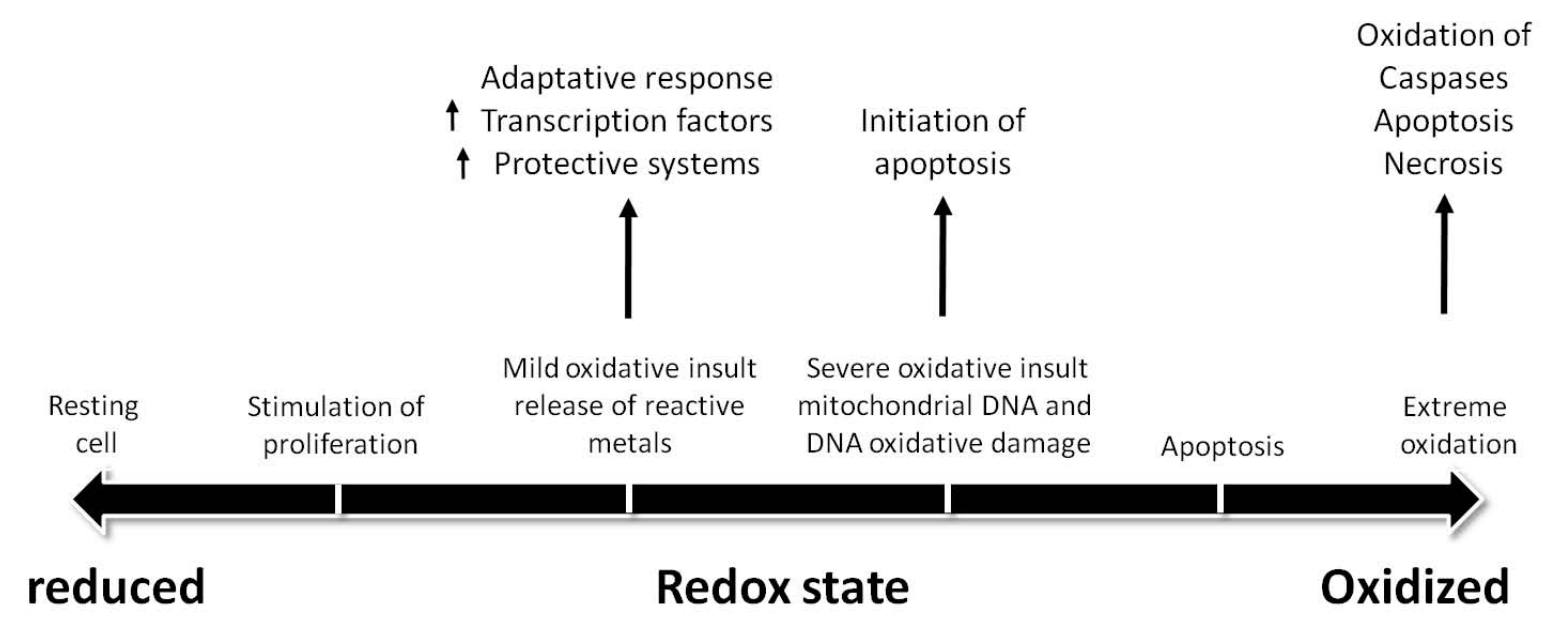

Fig. (1). Biological relevance of cellular redox status. The figure describes the physio-pathological events related to changes in redox balance. Slight increases of intracellular oxidation constitute reversible inputs leading to the activation of signal pathways necessary for the normal cell metabolism. Mild oxidative insult can be managed by cellular adaptive responses. A sustained or prolonged oxidative injury causes irreversible damage of biological molecules, cell dysfunction and death. The figure was kindly provided by PG Mastroberardino.

electrons, which will overwhelm the cellular buffering systems (GSH, thioredoxins) and the protein thiol pool. Therefore, a variety of molecular species such as DNA, membrane lipids and protein structure and functions will be affected $[6,7]$ causing cellular dysfunction and damage (Fig. 1).

The brain is particularly susceptible to oxidative stress because it utilizes the highest amount of oxygen compared with other organs. The brain also contains high concentrations of polyunsaturated fatty acids that are prone to lipid peroxidation and is rich in iron, which can catalyse hydroxyl radical formation [8-10]. Oxidative stress results in functional cellular disruption and cellular damage and may cause subsequent cell death via oxidation of biomolecules such as proteins, lipids, and nucleic acids. Protein oxidation leads to functional changes or deactivation of various enzymes [6]. Lipid peroxidation causes membrane structure alterations that affect membrane fluidity and permeability and membrane protein activity [7]. Oxidative stress is involved in normal conditions such as aging processes and in the pathogenesis of a number of neurologic and neurodegenerative disorders, including Alzheimer's disease and Parkinson's disease (PD), amyotrophic lateral sclerosis and epilepsy [11-15].

Dopamine (DA) neurons in the substantia nigra pars compacta (SNc) selectively degenerate in PD [15-17]. Their particular physiology is intrinsically associated with elevated ROS production. DA neurons are spontaneous pacemaking cells, and generate rhythmic action potentials in the absence of synaptic inputs. While most neuronal types use $\mathrm{Na}+$ to generate their action potentials, SNc DA neurons rely on $\mathrm{Ca}^{2+}$, which enters the cytoplasm through L-type channels [18-20]. Over time, the spontaneous activity of these neurons could lead to elevated and harmful concentrations of cytosolic $\mathrm{Ca}^{2+}$. This potential harm can be prevented by the buffering activity of certain organelles, such as mitochondria. However, this activity is invariably associated with ROS production [21, 22]. In addition, excess ROS could derive directly from DA metabolism, which generates harmful by-products such as semiquinones and hydrogen peroxide [23]. The overall result is an increase in the basal levels of ROS in SNc DA neurons that impairs their ability to tolerate further oxidative insults. In fact, systemic administrations of pro-oxidants, which target every cell in the brain, results in selective damage of the DA system, and chronic administration of ROS producers, such as rotenone, 6-hydroxydopamine and paraquat, mimic PD pathogenesis [24-26]. DA release is constantly accompanied by a concomitant increase in the rate of DA synthesis [27].

Tyrosine hydroxylase (TH) is the first and rate-limiting enzyme in DA synthesis through the reaction of hydroxylation of L-tyrosine to L-3,4-dihydroxyphenylalanine (L-DOPA). TH activity is mainly modulated by phosphorylation at serine residues (Ser) Ser8, Ser19, Ser31 and Ser40 [28] by a variety of protein kinases. TH belongs to a family of iron-containing, biopterin-dependent amino acid hydroxylases that use tetrahydrobiopterin $\left(\mathrm{BH}_{4}\right)$ and $\mathrm{O}_{2}$ to hydroxylate L-tyrosine [29]. The $\mathrm{Fe}^{2+}$ is bound to $\mathrm{TH}$ and can be oxidized to $\mathrm{Fe}^{3+}$ in the presence of $\mathrm{O}_{2}$, forming bonds with catechols and enabling a feedback inhibitor process [30]. These two primary regulatory mechanisms of $\mathrm{TH}$ function can be strongly affected by changes redox state.

Peroxynitrite $\left(\mathrm{ONOO}^{-}\right)$is perhaps best known for its ability to nitrate free tyrosine or tyrosine residues in proteins [31]. $\mathrm{ONOO}^{-}$has been implicated as an etiological factor in the DA neuronal degeneration associated with PD and in other neurodegenerative and neurotoxic conditions [32, 33]. Exposure of $\mathrm{TH}$ to $\mathrm{ONOO}^{-}$inhibits its catalytic activity and results in extensive tyrosine nitration of the protein $[34,35]$. However, $\mathrm{ONOO}^{-}$is also a powerful oxidant. Interactions of $\mathrm{ONOO}^{-}$with intracellular thiols could readily alter its reactive properties and in the process, create downstream reactants (e.g., S-nitrosothiols) that have equal potential to modify critical cellular proteins [36]. Phosphorylation of Ser residues on $\mathrm{TH}$ can differently affect not only the activity but also enzyme stability or its degradation [37]. Experimental evidence has demonstrated that oxidative stress can also 
affect $\mathrm{TH}$ metabolism and turnover by affecting the mechanisms of Ser phosphorylation in $\mathrm{TH}[38,39]$. The main long-term regulatory mechanisms of $\mathrm{TH}$ activity rely on TH gene expression [30].

The DA-ergic dysfunction in brain is always associated with a decrease of $\mathrm{TH}$ expression related to DA neuron loss, increase of $\mathrm{TH}$ degradation and altered gene regulation. Substantial evidence exists supporting the crucial role of oxidative injury in the alteration of TH gene expression. The redox-sensitive factors Zinc finger regulatory proteins [40], DJ-1 [41] and estrogen exposure [42] have been considered the major oxidative stress-related factors leading to altered expression of $\mathrm{TH}$.

In this review, we will discuss the oxidative mechanisms of neurotoxicity in DA neurons, and provide an overview of the most relevant findings showing the biological relevance of oxidative stress-mediated $\mathrm{TH}$ activity, metabolism and expression mechanisms and their possible implications in the development of neurodegenerative disorders.

\section{OXIDATIVE STRESS AND DOPAMINERGIC DAMAGE}

The brain is characterized by extraordinary functional complexity. It is likely that the intracellular redox state and its homeostasis differ among cell types. In this respect, recent in vitro and in vivo studies investigating the neuronal redox response, have shown that DA neurons are particularly vulnerable to pro-oxidant stimuli [21, 43], and under basal conditions, the intracellular redox state is more oxidized in DA neurons than in others [15, 44] (Fig. 2).

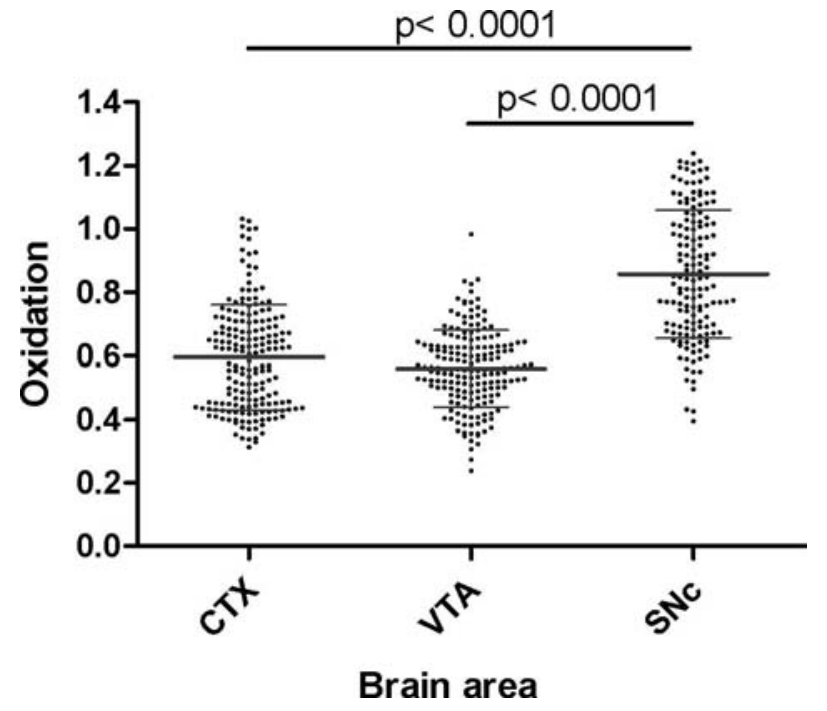

Fig. (2). Intracellular redox state of DA-ergic neurons of the substantia nigra pars compacta $(\mathrm{SNc})$ in normal rats. The basal intracellular redox state of DA neurons in the $\mathrm{SNc}$ is more oxidized than that of DA neurons of the ventral tegmental area (VTA) or cortical neurons. (From: Horowitz, Milanese Di Maio et al., 2011). This phenomenon finds an explanation in the particular biology of DA-ergic neurons of SNc.

This phenomenon observed in DA neurons of the SNc may be explained by their particular physiology. In fact, DA neurons do not require synaptic inputs since they are characterized by a spontaneous pacemaking activity, mediated by L-type $\mathrm{Ca}^{2+}$ channels $[19,20]$ and each action potential is associated with a robust $\mathrm{Ca}^{2+}$ influx. The consequent increase of cytosolic $\mathrm{Ca}^{2+}$ concentration could constitute a harmful event for the cell. Under physiological conditions this phenomenon is prevented by extrusion mechanisms of $\mathrm{Ca}^{2+}$ and endoplasmic reticulum $\mathrm{Ca}^{2+}$ uptake. This protective action is carried out as well by mitochondria. The $\mathrm{Ca}^{2+}$ influx into the mitochondrial matrix neutralizes the trans-membrane proton gradient, with a resultant increase in activity of respiratory complexes. Intrinsic to this process is an increased production of ROS. Over time, the continuous activity of DA neurons may lead to increased ROS levels and thus to a more oxidized intracellular redox state. The mitochondrial physiology, influenced by a particular use of $\mathrm{Ca}^{2+}$, could also provide a partial explanation for the amplified response observed in DA neurons exposed to toxicants causing mitochondrial impaired function, when compared to cortical neurons.

The redox state of thiols exerts a profound effect on the physiology of neurons; for instance, it regulates fundamental processes such as synaptic plasticity [45] and controls the conductance of several ion channels involved in neuronal excitability [46, 47]. Additionally, thiol oxidation has been involved in zinc finger transcription factor activity [48], transferrin mediated iron accumulation [49], and decrease of TH activity [36].

Cysteine residues control the redox environment through reversible oxidation of thiols to disulfides. As oxidative stress increases, a high number of Cys in the protein thiol pool will be oxidized to disulfides. The reversible conversion of thiols to disulfides is one the earliest observable events during radical-mediated oxidation of proteins [50, 51]. Thiol oxidation has functional consequences as it may be correlated to protein inactivation [1]. As the oxidative imbalance increases, amino acids other than Cys can be irreversibly oxidized; many of these modifications require more persistent oxidant conditions than disulfide formation [1]. Among the possible modifications, formation of carbonyls, which occurs especially on the side chains of Lys, Arg, Pro and Val, is the most extensively studied [1]. Carbonyl formation has been detected in DA-ergic dysfunctions induced by toxicants $[52,53]$. Carbonyl formation can be induced by different oxidizing agents and often results in loss of protein function [54]. Carbonyls are relatively difficult to induce compared to Cys oxidation and indeed, high carbonyl levels tend to indicate that oxidative stress is already associated with some kind of disease related dysfunction $[55,56]$.

A further set of oxidative modifications that can affect proteins derives from the interaction of nitric oxide with molecular oxygen to generate $\mathrm{ONOO}^{-}$which, in turn, can react with some side chain amino acids, including tyrosines and Cys, to form respectively nitrotyrosine and nitrosocysteine. Importantly, neuronal inflammation related to pro-oxidant toxins involves the up-regulation of inducible nitric oxide synthese as well as activation of NADPH oxidases [16]. This sequence of events favours the production of $\mathrm{ONOO}^{-}$, which has been strongly implicated in the DA-ergic neurotoxicity in PD pathogenesis [57]. 


\section{REGULATION OF TH ACTIVITY}

The active form of $\mathrm{TH}$ is a tetramer with a molar mass of approximately $240 \mathrm{kDa}$ [30] with high homology in terms of sequence and catalytic mechanisms to phenylalanine hydroxylase and tryptophan hydroxylase (TPH). TH catalyses the initial and rate-limiting step in the biosynthesis of the catecholamines (CAs) DA, noradrenaline and adrenaline. In TH-mediated reaction, dioxygen, L-tyrosine, and $\mathrm{BH}_{4}$ are converted to L-DOPA and 4a-hydroxytetrahydrobiopterin $\left(4 \mathrm{aOH}-\mathrm{BH}_{4}\right)$ [58]. Phosphorylation mechanisms are the primary biochemical events responsible for $\mathrm{TH}$ activation and CAs homeostasis maintenance in tissues. The regulation of $\mathrm{TH}$ activity is accomplished by dynamic changes in the phosphorylation state of the enzyme and four phosphorylation sites have been identified, Ser8, Ser19, Ser31, and Ser40 by a variety of protein kinases (Fig. 2). Each catalytically active subunit of all aromatic amino acid hydroxylases contains a single atom of non-heme iron.

The hydroxylation of L-tyrosine to L-DOPA catalysed by $\mathrm{TH}$ in the presence of $\mathrm{BH}_{4}$ and $\mathrm{O}_{2}$ requires the reduced status of the iron atom $\left(\mathrm{Fe}^{2+}\right)$ in the catalytic site. $\mathrm{Fe}^{2+}$ during the reaction becomes oxidized to $\mathrm{Fe}^{3+}$ by $\mathrm{O}_{2}$ and in this form, binds catechols to become inactive (Fig. 3). The chemical interaction of $\mathrm{Fe}^{3+}$-catechols represents the main mechanism of feedback leading to enzyme inactivation and stabilization under physiological conditions. Indeed, as a result of this reaction, TH activity is inhibited by a binding competition of catechols with $\mathrm{BH}_{4}$ for binding of the ferric iron at the catalytic site of the enzyme. This is a classic kinetic mediated, reversible inhibition and acts as a sensor of the local concentrations of the catechols. Furthermore, catechols can bind almost irreversibly with ferric iron at the $\mathrm{TH}$ catalytic site [30]. Phosphorylation mechanisms and catechol-mediated TH inhibition can interact to further modulate the enzyme activity. Phosphorylation of $\mathrm{TH}$, indeed, alters the enzyme's conformation leading to a form of TH that is still inhibited, but with an increased rate of dissociation of the bound CAs- $\mathrm{Fe}^{3+}$ [59]. Loss of CAs binding allows the $\mathrm{Fe}^{3+}$ to be reduced by $\mathrm{BH}_{4}$, thereby returning the enzyme to the fully active state. TH is subject to feedback inhibition by a range of catechols but the physiologically relevant CAs DA, noradrenaline and adrenaline all have the highest affinity [60]. The most likely candidates for the phosphorylation of Ser19, Ser31, and Ser40 are calcium/calmodulin-dependent protein kinase II, mitogen-activated protein kinase, and protein kinase A, respectively. The phosphorylation of Ser40 has the major effect on TH activity [37].

\section{REDOX-MEDIATED MODULATION OF TH ACTIVITY}

DA neurons are particularly prone to damage caused by aging, neurological disease, drugs and environmental contaminants [61-63]. PD, for instance, is a neurodegenerative disorder characterized, in part, by the progressive and selective loss of DA-ergic neuron cell bodies within the SNc and the associated deficiency of DA in the striatum, which gives rise to the typical motor symptoms. Data from epidemiological studies in humans and molecular studies in genetic, as well as in toxin-induced animal models of $\mathrm{PD}$, indicate that mitochondrial dysfunction and oxidative stress occurs early in the pathogenesis of this neurodegenerative disorder [64].

Mechanistic studies carried out in the past years in different animal models of PD have increasingly focused on oxidative stress as crucial phenomenon in the DA dysfunction. More recently, it has become evident that TH function can be altered under conditions of oxidative and nitrosative stress through direct modification of the protein. $\mathrm{ONOO}^{-}$inhibits TH catalytic function via a mechanism that involves nitration of tyrosine residues [35] or direct oxidation of Cys residues [65, 66].

Carbonylation, sulfenic or sulfonic acid in proteins are related to irreversible structural and functional modifications, and represent a potentially harmful consequence of oxidative stress. Thiol-containing small molecules like Cys and GSH participate in cellular redox homeostasis by preventing oxidative modification of proteins. However, increasing evidence shows that Cys or GSH, under oxidative conditions, can covalently modify proteins by forming mixed disulfides with them, a phenomenon defined as S-thiolation. S-Thiolation is a dynamic regulatory mechanism that has many parallels with protein phosphorylation, and target-dependent functional consequences. The consequences of S-thiolation on a specific thiol residue in a specific protein are hard to predict, since it can be protective by masking of a critical Cys against irreversible oxidation or cause loss of function [67]. A growing number of proteins are now known to be modified by S-thiolation, including TH [36].

$\mathrm{ONOO}^{-}$is known to nitrate free tyrosine or tyrosine residues in proteins, and it has been implicated as an etiological factor in the DA neuronal degeneration associated with PD and in other neurodegenerative diseases [32]. Exposure of $\mathrm{TH}$ to $\mathrm{ONOO}^{-}$inhibits its catalytic activity and results in extensive tyrosine nitration of the protein. Furthermore, given the pro-oxidant property of $\mathrm{ONOO}^{-}$, a recent study suggests that oxidized forms of Cys or GSH (e.g. GS (O) SG) are produced in the reaction with $\mathrm{ONOO}^{-}$ or $\mathrm{NO}_{2}$ and mediate S-thiolation of TH [36].

The observation of elevated levels of nitrotyrosine in chronically affected tissues and the fact that DA neurons express factors able to prevent the $\mathrm{ONOO}^{-}$-mediated tyrosine nitration, including DA itself [66], the TH cofactor $\mathrm{BH}_{4}$ [68], and reduced nicotinamide nucleotides [69], support the hypothesis that nitrotyrosine formation represents a late event in the process of degeneration of these neurons and is not an early sign of distress or damage [70], whereas, Cys and GSH could be among the factors that prevent the $\mathrm{ONOO}^{-}$-induced tyrosine nitration by $\mathrm{S}$-thiolation as a potential early response to stress. Experimental models of oxidative damage-mediated DA dysfunction have been invaluable to dissect the biochemical mechanisms of toxicity in DA-synthesizing cells. Increasing evidence obtained in toxin models of PD, for instance, provides an emerging emphasis on the crucial role of cellular oxidative injury on $\mathrm{TH}$ activity, an important aspect of PD pathogenesis $[38,39$, 71].

Recent experimental evidence shows that treatment with potent pro-oxidants in different DA cells lines causes a sustained TH phosphorylation [39]. Particular emphasis has 


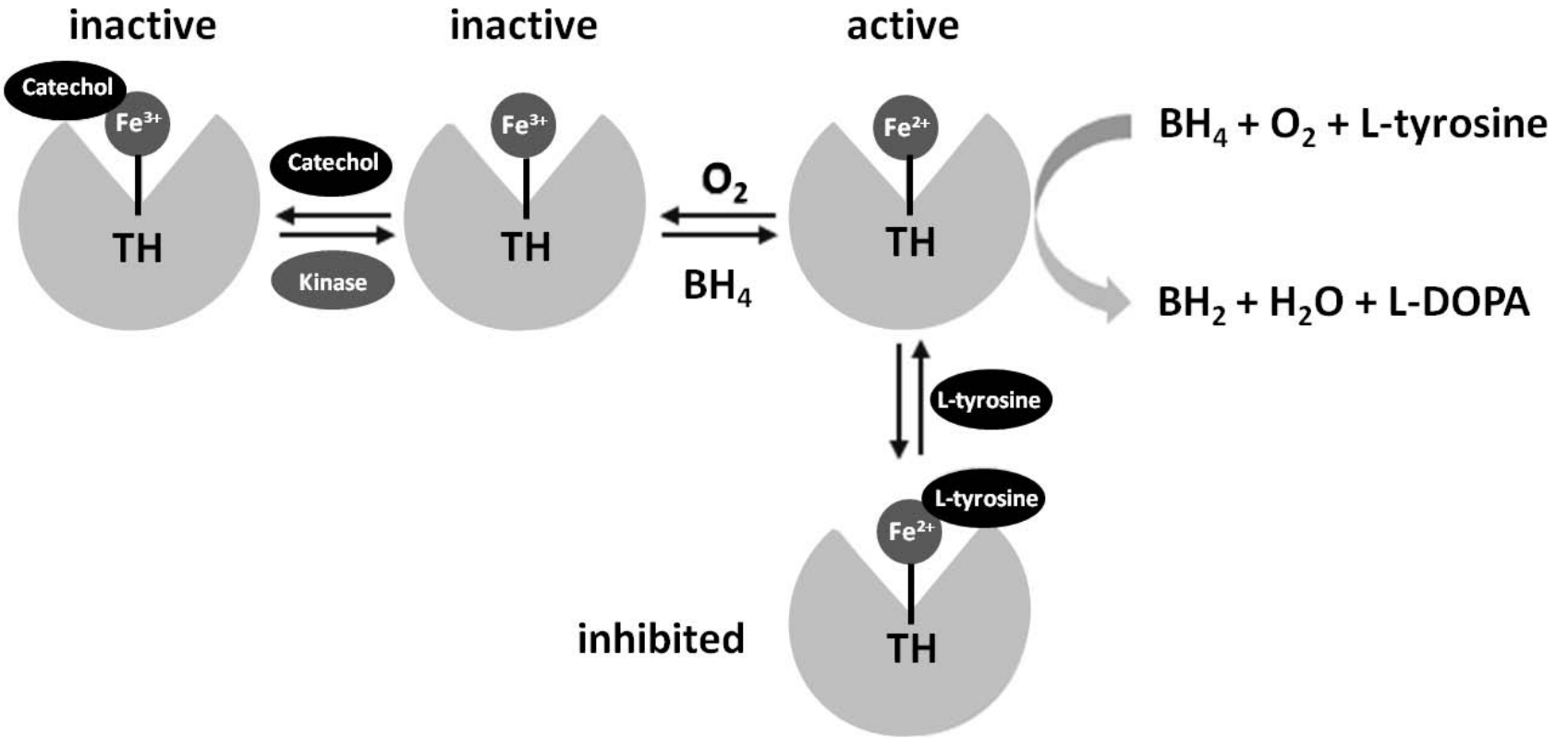

Fig. (3). Regulatory feedback mechanisms of TH activity (model of Ramsey and Fitzpatrick). The active form of TH contains reduced iron $\left(\mathrm{Fe}^{2+}\right)$. A sustained production of catechol can induce inactivation by oxidation of the $\mathrm{Fe}^{2+}$ to $\mathrm{Fe}^{3+}$ and subsequent catechol binding or by binding to the substrate L-tyrosine at high concentrations. TH can be activated by protein phosphorylation and reduction of iron with tetrahydrobiopterin $\left(\mathrm{BH}_{4}\right)$.

been given to the mechanisms of phosphorylation of Ser 19, Ser 31 and Ser 40, for their crucial role in TH activity and metabolism. Recently, it was proposed that phosphorylation at Ser40 of $\mathrm{TH}$ is entirely routed by the cAMP-dependent kinase, phosphokinase A [72]. In support of the redox modulation of this pathway of TH phosphorylation at Ser40, a crucial regulatory event of TH activity, it has been shown that the oxidative injury induced by $\mathrm{H}_{2} \mathrm{O}_{2}$ and 1-methyl-4phenylpyridinium treatment in SH-SY5Y cells causes the TH phosphorylation at Ser40 via cAMP-dependent messenger cascades. This phenomenon was abolished by treatment with melatonin [38].

Recently, abnormality of the degradation of intracellular proteins has been addressed as a major cause of neurodegeneration. DA-ergic dysfunctions are characterized by reduction of $\mathrm{TH}$ in $\mathrm{DA}$ neurons. For this reason, $\mathrm{TH}$ expression has been widely used as a marker of DA-ergic function. Studies aimed to assess the degradation mechanism regulating the protein level of $\mathrm{TH}$, have highlighted the importance of phosphorylation at different Ser residues in stabilizing the enzyme [73]. However, some reports indicate that the phosphorylation of hydroxylases induces their degradation by proteasomes. For example, the phosphorylation of TPH is a prerequisite for the ubiquitinproteasome pathway activation leading to the degradation of TPH [74]. TH phosphorylated at its Ser40 is prone to be insoluble and aggregated by dysfunction of the ubiquitinproteasome pathway in PC12D cells [75].

Thus, based on the fact that changes in intracellular redox status can affect directly the phosphorylation mechanisms at Ser40 of $\mathrm{TH}$, it is possible to hypothesize that oxidative stress might influence $\mathrm{TH}$ metabolism causing short-term alterations of DA homeostasis in affected cells.
Thiol oxidation is the principal mechanism integrating intracellular redox state with signalling pathways [76]. Extracellular signal-regulated kinases $1 / 2$ (ERK 1/2) is a member of the mitogen activated protein kinase pathway that is known to promote cell survival and is activated during redox imbalance [77]. Moreover, ERK 1/2 signalling is implicated in the phosphorylation of Ser31 of $\mathrm{TH}$ modulating its stability [37]. The evidence that, in a synchronized manner, cellular oxidation anticipates ERK 1/2 phosphorylation with a consequent reduction of the cellular environment [44], and that the over-expression of $\mathrm{TH}$ improves the cellular resistance against cell death induced by oxidative stressors [71], supports the idea that TH activity and metabolism could contribute to the cellular redox homeostasis

\section{OXIDATIVE STRESS AND TH ACTIVITY IN AGING}

Impaired function in the central nervous system during aging is accompanied by changes in various neurotransmitter systems [78, 79]. Decreases in DA content [80] and DA turnover [81] have been reported to occur during aging in the rat nigrostriatal system. The fact that such decrease in DAergic metabolism could be accompanied by loss of nigral DA-ergic neurons during aging in mammals remains controversial, since contrasting data show no age-related changes in DA neurons in humans [82, 83]. The decrease of endogenous anti-oxidant defences and the oxidant molecules generated during normal metabolism appear to play a significant role in the processes of aging. Thus, the main mechanisms of alteration in DA-ergic functions might be related prevalently to the increase of oxidative damage. This hypothesis is further supported by the fact that aged animals are more susceptible to DA-related neurodegenerative disorders. Additionally, experimental evidence reports the ameliorative effect of the DA precursor, L-DOPA, in a toxin 
model of PD developed in aged rats [84], suggesting that oxidative impairment of $\mathrm{TH}$ could be the determinant factor in the occurrence of the DA-ergic dysfunction in aging and as well as in DA dysfunctions.

A study conducted by De La Cruz et al. [63] showed that $\mathrm{TH}$ activity significantly decreases $(55 \%)$ in rat brain $\mathrm{SNc}$ during aging. In particular, these findings describe a major role of oxidative damage in the accumulation of carbonylated inactive $\mathrm{TH}$, more in $\mathrm{SNc}$ than in striatum of aged rat. This phenomenon occurring in $\mathrm{SNc}$ during aging provides further insights on the crucial role of $\mathrm{TH}$ in the higher vulnerability of DA neurons to oxidative damage.

In summary, DA-ergic oxidative damage in aging processes has some parallels to the pathogenesis of degenerative diseases affecting $\mathrm{SNc}$, and has also been considered one of the most crucial para-physiological phenomena leading DA neurons to a status that is more prone to degeneration.

\section{OXIDATIVE STRESS AND TH EXPRESSION}

Transcriptional regulation of the $\mathrm{TH}$ gene constitutes one of the main long-term regulatory mechanisms of $\mathrm{TH}$ expression. Thus, given the crucial role of intracellular redox status in modulating $\mathrm{TH}$ gene expression, neuronal oxidative injury can cause impairment in physiological levels of TH and the consequent DA dysfunction in aging and in neurodegenerative disorders involving the DA-ergic system.

Given its specific localization, TH is one of the main biomarkers used to assess the DA-ergic phenotype and function. Several recent studies have reported that antioxidant molecule treatment elicits recovery of $\mathrm{TH}$ expression in different models of DA-ergic dysfunction [8588]. Interestingly, for instance, antioxidant properties of lithium treatment in animal models of neurodegeneration have been reported [89-91]. Moreover, lithium treatment shows efficacy in increasing TH expression [92, 93]; however, this is still controversial [94]. Despite these latest findings, it is not yet known whether the anti-oxidant mechanisms enhanced by lithium administration are involved in the modulation of TH expression. TH downregulation is a common sign of DA-ergic degeneration and might be caused by both altered gene functions and neurotoxicity-mediated protein synthesis impairment. Oxidative stress occurring during DA-ergic neurodegeneration might specifically affect the molecular mechanisms of $\mathrm{TH}$ expression. Therefore, despite the increasing amount of experimental evidence in this research area, the biochemical mechanisms by which oxidative stress might directly affect TH expression remain underexplored. Additionally, the aforementioned findings do not provide further insight into the topic. Here we report the latest research evidence on the possible oxidation-related regulatory mechanisms of $\mathrm{TH}$ expression.

Intracellular $\mathrm{Zn}^{2+}$ is involved in facilitating physiological processes. This essential transition element is contained in structural or functional domains of several proteins, including enzymes necessary for replication, transcription and translation, cell division and differentiation [95]. Depending upon its concentration, $\mathrm{Zn}^{2+}$ may be neuroprotective or neurotoxic by means of its antioxidant and pro-oxidant properties. Excess of intracellular $\mathrm{Zn}^{2+}$ or long-term exposure to $\mathrm{Zn}^{2+}$ induces DA-ergic neurodegeneration in rats [40, 96, 97]. Furthermore, high levels of $\mathrm{Zn}^{2+}$ are associated with neurodegenerative diseases, including Alzheimer's disease and PD [98, 99]. Recent studies have provided further insights in the mechanisms of DA-ergic neurodegeneration induced by high levels of $\mathrm{Zn}^{2+}$. In particular, Kumar et al. [40] have shown that $\mathrm{Zn}^{2+}$-mediated DA neuron loss is related to an increased lipoxygenase, superoxide dismutase, heme oxygenase- 1 and decreased catalase, and glutathione-S-transferase activities and $\mathrm{TH}$ expression.

Changes in cellular redox status can directly or indirectly affect pathways for the regulation of gene expression. Reductive or oxidative stresses can modulate the transcription of certain genes by pathways that probably involve protein kinases [100-103]. Additionally, the cellular response to severe oxidative conditions may affect, through the oxidation or alkylation of thiol residues, the binding mechanisms of nucleic acid regulatory factors, which can be directly activated or inactivated.

Zinc finger proteins constitute the main cellular DNAregulatory system [104, 105]. They all contain redox regulation cysteine residues as part of the metal-binding, DNA-intercalating fingers [106, 107]. The zinc finger domain of these proteins binds with different affinities to specific nucleotidic sequences (e.g. TATA or CAAT box elements) in proximal promoter sites of genes and it contributes to the transcriptional regulation of numerous genes, including the TH gene [108-110]. Some of these transcription factors appear to become progressively oxidized during aging, resulting in the reversible loss of binding activity [111]. It has been hypothesized that Cys residues may constitute redox switches which directly regulate gene expression $[112,113]$.

DJ-1(PARK7) is a multifunctional protein, and loss of its functions or expression is thought to be responsible for onset of familial and sporadic PD [114, 115]. Mutations and increased ubiquitin-proteasome system degradation of DJ-1 have been described in patients with familial PD $[116,117]$ and in experimental models of PD [118]. DJ-1 belongs to the peptidase C56 family of proteins. It acts as a positive coactivator of various transcription factors regulating expression of several genes, including TH by means of its interaction with the metastasis associated protein 1 coregulator [119]. It may also function as a redox-sensitive chaperone, as a sensor for oxidative stress, and it apparently protects neurons against oxidative stress and cell death.

Cys residues of DJ-1 (Cys-46, Cys-53, and Cys-106) are oxidized during cellular oxidative stress, resulting in scavenging of ROS [120-122] and in the functional response of the protein. The anti-oxidant function of DJ-1 might therefore be routed by self-oxidation of Cys residues and by activation of redox-related genes. The transcription repressor, PTB-associated splicing factor (PSF), has a specific binding site on the TH gene promoter. It has been reported that human DJ-1 binds to PSF to sequester the $\mathrm{PSF} /$ co-repressor complex, leading to induction of TH gene expression [123]. Studies aimed to evaluate the protective mechanisms of DJ-1 have shown that nigral injection of DJ1 restored DA metabolism in 6-hydroxydopamine-treated 


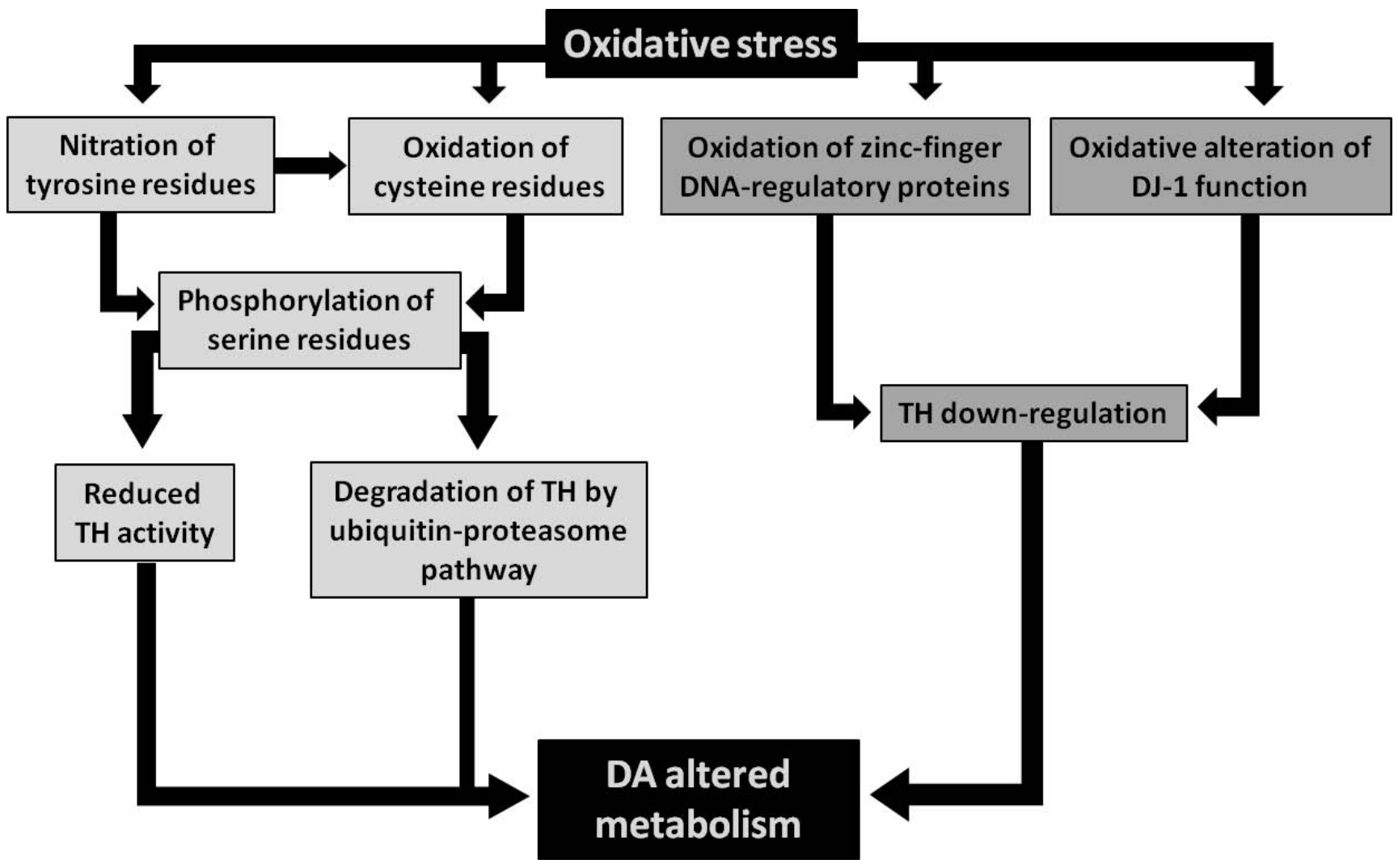

Fig. (4). Schematic summary of oxidation-mediated TH activity, metabolism and expression alterations. An intracellular oxidative environment affects the phosphorylated status of TH by thiol oxidation, carbonylation, nitration and S-thyolation of cysteine residues in the enzyme. This results in inhibition of TH activity and increased degradation rate of TH. Oxidative stress can also affect negatively TH gene expression by mediating a functional impairment of the zinc-finger DNA-regulating proteins and the transcription factor DJ-1. Reduction of TH activity, increased TH degradation and TH gene down-regulation might represent critical phenomena leading to DA-ergic dysfunction.

animals by binding directly to TH and L-dopa decarboxylase in a manner dependent on the oxidative state of Cys-106, thereby stimulating their activities. Taken together, these findings indicate DJ-1 as a extra-neuronal essential factor in the redox-dependent regulation of $\mathrm{TH}$ expression and activity and the consequent DA homeostasis, which is crucial to the pathogenesis of DA-linked neurodegenerative disease.

\section{CONCLUSIONS}

DA cells possess a distinct physiology intrinsically associated with elevated ROS production, and selectively degenerate under oxidative stress conditions. Increased free radical production, mitochondrial dysfunction and impaired antioxidant defences system are, therefore, the key players contributing to DA-ergic-linked neurological disorders.

In the last decades several studies of extreme interest have been conducted to provide further insights in the intracellular redox-related pathogenic mechanisms in DA neurons. The key role of $\mathrm{TH}$ function in maintaining the physiological levels of DA in brain has prompted investigators to investigate the possible implications of oxidative stress in the dysfunctions of this enzyme during DA neurodegeneration. $\mathrm{TH}$ is a promising drug target for these diseases, but no structural information is currently available to assist in drug development. Furthermore, the redox mechanisms that modulate $\mathrm{TH}$ activity, metabolism and expression (Fig. 4) are not well understood, although an increasing number of scientific contributions are focusing on the biological relevance of this phenomenon.

The aim of this review has been, therefore, to provide an overview of this under explored research field and further crucial information for understanding the redox-mediated mechanisms in healthy and diseased brain.

\section{ACKNOWLEDGEMENTS}

We sincerely acknowledge the Ri.MED Foundation, Italy for support of RD. This study was supported in part by University of Malta research funding, coordinator GDG.

\section{CONFLICTS OF INTEREST}

Declared none.

$\begin{array}{lll}\text { ABBREVIATIONS } & \\ \mathrm{BH}_{4}= & \text { Tetrahydrobiopterin } \\ \mathrm{CAs}= & \text { Catecholamines } \\ \mathrm{Cys}= & \text { Cysteine } \\ \mathrm{DA}= & \text { Dopamine }\end{array}$




$\begin{array}{lll}\text { L-DOPA } & =\quad \text { L-3,4-dihydroxyphenylalanine } \\ \text { ERK 1/2 } & \text { Extracellular regulated kinase 1/2 } \\ \text { GSH }= & \text { Reduceed glutathionine } \\ \text { PD }= & \text { Parkinson's disease } \\ \mathrm{ONOO}^{-}= & \text {Peroxynitrite } \\ \mathrm{PD}= & \text { Parkinson's disease } \\ \mathrm{PSF}= & \text { PTB-associated splicing factor } \\ \text { ROS }= & \text { Reactive oxygen species } \\ \text { Ser } & = & \text { Serine } \\ \text { SNc } & \text { Substantia nigra pars compacta } \\ \mathrm{TH} & = & \text { Tyrosine hydroxylase } \\ \mathrm{TPH} & = & \text { Tryptophan hydroxylase }\end{array}$

\section{REFERENCES}

[1] Shacter, E. Quantification and significance of protein oxidation in biological samples. Drug Metab. Rev., 2000, 32(3-4), 307-326.

[2] Jones, D.P.; Go, Y.M.; Anderson, C.L.; Ziegler, T.R.; Kinkade, J.M., Jr.; Kirlin, W.G. Cysteine/cystine couple is a newly recognized node in the circuitry for biologic redox signaling and control. FASEB J., 2004, 18(11), 1246-1248.

[3] Schafer, F.Q.; Buettner, G.R. Redox environment of the cell as viewed through the redox state of the glutathione disulfide/glutathione couple. Free Radic. Biol. Med., 2001, 30(11), 1191-1212.

[4] Bader, M.; Muse, W.; Ballou, D.P.; Gassner, C.; Bardwell, J.C. Oxidative protein folding is driven by the electron transport system. Cell, 1999, 98(2), 217-227.

[5] Paget, M.S.; Buttner, M.J. Thiol-based regulatory switches. Ann. Rev. Genet., 2003, 37, 91-121.

[6] Stadtman, E.R. Protein oxidation in aging and age-related diseases. Ann. NY Acad. Sci., 2001, 928, 22-38.

[7] Wong-Ekkabut, J.; Xu, Z.; Triampo, W.; Tang, I.M.; Tieleman, D.P.; Monticelli, L. Effect of lipid peroxidation on the properties of lipid bilayers: a molecular dynamics study. Biophys. J., 2007, 93(12), 4225-4236.

[8] Halliwell, B. Antioxidant defence mechanisms: from the beginning to the end (of the beginning). Free Radic. Res., 1999, 31(4), 261272

[9] Mariani, E.; Polidori, M.C.; Cherubini, A.; Mecocci, P. Oxidative stress in brain aging, neurodegenerative and vascular diseases: an overview. J. Chromatogr. B Analyt. Technol. Biomed. Life Sci., 2005, 827(1), 65-75.

[10] Jellinger, K.A. General aspects of neurodegeneration. J. Neural Transm. Suppl., 2003, 65, 101-144.

[11] Migliore, L.; Fontana, I.; Colognato, R.; Coppede, F.; Siciliano, G.; Murri, L. Searching for the role and the most suitable biomarkers of oxidative stress in Alzheimer's disease and in other neurodegenerative diseases. Neurobiol. Aging, 2005, 26(5), 587595

[12] Perry, G.; Nunomura, A.; Hirai, K.; Zhu, X.; Perez, M.; Avila, J.; Castellani, R.J.; Atwood, C.S.; Aliev, G.; Sayre, L.M.; Takeda, A.; Smith, M.A. Is oxidative damage the fundamental pathogenic mechanism of Alzheimer's and other neurodegenerative diseases? Free Radic. Biol. Med., 2002, 33(11), 1475-1479.

[13] Ashrafi, M.R.; Shams, S.; Nouri, M.; Mohseni, M.; Shabanian, R.; Yekaninejad, M.S.; Chegini, N.; Khodadad, A.; Safaralizadeh, R. A probable causative factor for an old problem: selenium and glutathione peroxidase appear to play important roles in epilepsy pathogenesis. Epilepsia, 2007, 48(9), 1750-1755.

[14] Di Maio, R.; Mastroberardino, P.G.; Hu, X.; Montero, L.; Greenamyre, J.T. Pilocapine alters NMDA receptor expression and function in hippocampal neurons: NADPH oxidase and ERK1/2 mechanisms. Neurobiol. Dis., 2011, 42(3), 482-495.

[15] Esposito, E.; Di Matteo, V.; Di Giovanni, G. Death in the substantia nigra: a motor tragedy. Expert Rev. Neurother., 2007, 7(6), 677-697.
[16] Rinne, J.O. Nigral degeneration in Parkinson's disease. Mov. Disord. 1993, 8(Suppl 1), S31-S35.

[17] Bjorklund, A.; Dunnett, S.B. Dopamine neuron systems in the brain: an update. Trends Neurosci., 2007, 30(5), 194-202.

[18] Bonci, A.; Grillner, P.; Mercuri, N.B.; Bernardi, G. L-Type calcium channels mediate a slow excitatory synaptic transmission in rat midbrain dopaminergic neurons. J. Neurosci., 1998, 18(17), 66936703

[19] Nedergaard, S.; Flatman, J.A.; Engberg, I. Nifedipine- and omegaconotoxin-sensitive $\mathrm{Ca} 2+$ conductances in guinea-pig substantia nigra pars compacta neurones. J. Physiol., 1993, 466, 727-747.

[20] Puopolo, M.; Raviola, E.; Bean, B.P. Roles of subthreshold calcium current and sodium current in spontaneous firing of mouse midbrain dopamine neurons. J. Neurosci., 2007, 27(3), 645-656.

[21] Chan, C.S.; Gertler, T.S.; Surmeier, D.J. A molecular basis for the increased vulnerability of substantia nigra dopamine neurons in aging and Parkinson's disease. Mov. Disord., 2010, 25(Suppl 1), S63-S70.

[22] Chan, C.S.; Guzman, J.N.; Ilijic, E.; Mercer, J.N.; Rick, C.; Tkatch, T.; Meredith, G.E.; Surmeier, D.J. 'Rejuvenation' protects neurons in mouse models of Parkinson's disease. Nature, 2007, 447(7148), 1081-1086

[23] Jenner, P.; Olanow, C.W. Oxidative stress and the pathogenesis of Parkinson's disease. Neurology, 1996, 47(6 Suppl 3), S161-170.

[24] Betarbet, R.; Sherer, T.B.; MacKenzie, G.; Garcia-Osuna, M. Panov, A.V.; Greenamyre, J.T. Chronic systemic pesticide exposure reproduces features of Parkinson's disease. Nat. Neurosci., 2000, 3(12), 1301-1306.

[25] McCormack, A.L.; Thiruchelvam, M.; Manning-Bog, A.B.; Thiffault, C.; Langston, J.W.; Cory-Slechta, D.A.; Di Monte, D.A. Environmental risk factors and Parkinson's disease: selective degeneration of nigral dopaminergic neurons caused by the herbicide paraquat. Neurobiol. Dis., 2002, 10(2), 119-127.

[26] Di Matteo, V.; Pierucci, M.; Di Giovanni, G.; Di Santo, A.; Poggi, A.; Benigno, A.; Esposito, E. Aspirin protects striatal dopaminergic neurons from neurotoxin-induced degeneration: an in vivo microdialysis study. Brain Res., 2006, 1095(1), 167-177.

[27] Zigmond, R.E.; Schwarzschild, M.A.; Rittenhouse, A.R. Acute regulation of tyrosine hydroxylase by nerve activity and by neurotransmitters via phosphorylation. Ann. Rev. Neurosci., 1989, $12,415-461$

[28] Haycock, J.W. Phosphorylation of tyrosine hydroxylase in situ at serine 8, 19, 31, and 40. J. Biol. Chem., 1990, 265(20), 1168211691.

[29] Fitzpatrick, P.F. Tetrahydropterin-dependent amino acid hydroxylases. Ann. Rev., Biochem., 1999, 68, 355-381.

[30] Kumer, S.C.; Vrana, K.E. Intricate regulation of tyrosine hydroxylase activity and gene expression. J. Neurochem., 1996, 67(2), 443-462.

[31] Ischiropoulos, H. Biological selectivity and functional aspects of protein tyrosine nitration. Biochem. Biophys. Res. Commun., 2003, 305(3), 776-783.

[32] Good, P.F.; Hsu, A.; Werner, P.; Perl, D.P.; Olanow, C.W. Protein nitration in Parkinson's disease. J. Neuropathol. Exp. Neurol., 1998, 57(4), 338-342.

[33] Torreilles, F.; Salman-Tabcheh, S.; Guerin, M.; Torreilles, J. Neurodegenerative disorders: the role of peroxynitrite. Brain Res. Brain Res. Rev., 1999, 30(2), 153-163.

[34] Ara, J.; Przedborski, S.; Naini, A.B.; Jackson-Lewis, V.; Trifiletti, R.R.; Horwitz, J.; Ischiropoulos, H. Inactivation of tyrosine hydroxylase by nitration following exposure to peroxynitrite and 1methyl-4-phenyl-1,2,3,6-tetrahydropyridine (MPTP). Proc. Natl. Acad. Sci. USA, 1998, 95(13), 7659-7663.

[35] Blanchard-Fillion, B.; Souza, J.M.; Friel, T.; Jiang, G.C.; Vrana, K.; Sharov, V.; Barron, L.; Schoneich, C.; Quijano, C.; Alvarez, B. Radi, R.; Przedborski, S.; Fernando, G.S.; Horwitz, J.; Ischiropoulos, H. Nitration and inactivation of tyrosine hydroxylase by peroxynitrite. J. Biol. Chem., 2001, 276(49), 46017-46023.

[36] Sadidi, M.; Geddes, T.J.; Kuhn, D.M. S-thiolation of tyrosine hydroxylase by reactive nitrogen species in the presence of cysteine or glutathione. Antioxid. Redox Signal., 2005, 7(7-8), 863-869.

[37] Dunkley, P.R.; Bobrovskaya, L.; Graham, M.E.; von NagyFelsobuki, E.I.; Dickson, P.W. Tyrosine hydroxylase phosphorylation: regulation and consequences. J. Neurochem., 2004, 91(5), 1025-1043. 
[38] Chetsawang, B.; Chetsawang, J.; Govitrapong, P. Protection against cell death and sustained tyrosine hydroxylase phosphorylation in hydrogen peroxide- and MPP-treated human neuroblastoma cells with melatonin. J. Pineal Res., 2009, 46(1), $36-42$.

[39] Klongpanichapak, S.; Phansuwan-Pujito, P.; Ebadi, M.; Govitrapong, P. Melatonin inhibits amphetamine-induced increase in alpha-synuclein and decrease in phosphorylated tyrosine hydroxylase in SK-N-SH cells. Neurosci. Lett., 2008, 436(3), 309313.

[40] Singh, B.K.; Kumar, A.; Ahmad, I.; Kumar, V.; Patel, D.K.; Jain, S.K.; Singh, C. Oxidative stress in zinc-induced dopaminergic neurodegeneration: implications of superoxide dismutase and heme oxygenase-1. Free Radic. Res., 2011, 45(10), 1207-1222.

[41] Ishikawa, S.; Taira, T.; Niki, T.; Takahashi-Niki, K.; Maita, C.; Maita, H.; Ariga, H.; Iguchi-Ariga, S.M. Oxidative status of DJ-1dependent activation of dopamine synthesis through interaction of tyrosine hydroxylase and 4-dihydroxy-L-phenylalanine (L-DOPA) decarboxylase with DJ-1. J. Biol. Chem., 2009, 284(42), 2883228844.

[42] MohanKumar, S.M.; Kasturi, B.S.; Shin, A.C.; Balasubramanian, P.; Gilbreath, E.T.; Subramanian, M.; Mohankumar, P.S. Chronic estradiol exposure induces oxidative stress in the hypothalamus to decrease hypothalamic dopamine and cause hyperprolactinemia. Am. J. Physiol. Regul. Integr. Comp. Physiol., 2010, 300(3), R693R699.

[43] Jenner, P. Oxidative stress in Parkinson's disease. Ann. Neurol., 2003, 53(Suppl 3), S26-S36; discussion S36-S38.

[44] Horowitz, M.P.; Milanese, C.; Di Maio, R.; Hu, X.; Montero, L.M.; Sanders, L.H.; Tapias, V.; Sepe, S.; van Cappellen, W.A.; Burton, E.A.; Greenamyre, J.T.; Mastroberardino, P.G. Single-cell redox imaging demonstrates a distinctive response of dopaminergic neurons to oxidative insults. Antioxid. Redox Signal., 2011, 15(4), 855-871.

[45] Bodhinathan, K.; Kumar, A.; Foster, T.C. Intracellular redox state alters NMDA receptor response during aging through $\mathrm{Ca} 2+/$ calmodulin-dependent protein kinase II. J. Neurosci., 2010, 30(5), 1914-1924.

[46] Cai, S.Q.; Sesti, F. Oxidation of a potassium channel causes progressive sensory function loss during aging. Nat. Neurosci., 2009, 12(5), 611-617.

[47] Gamper, N.; Zaika, O.; Li, Y.; Martin, P.; Hernandez, C.C.; Perez, M.R.; Wang, A.Y.; Jaffe, D.B.; Shapiro, M.S. Oxidative modification of M-type $\mathrm{K}(+)$ channels as a mechanism of cytoprotective neuronal silencing. EMBO J., 2006, 25(20), 49965004 .

[48] Wu, X.; Bishopric, N.H.; Discher, D.J.; Murphy, B.J.; Webster, K.A. Physical and functional sensitivity of zinc finger transcription factors to redox change. Mol. Cell Biol., 1996, 16(3), 1035-1046.

[49] Mastroberardino, P.G.; Hoffman, E.K.; Horowitz, M.P.; Betarbet, R.; Taylor, G.; Cheng, D.; Na, H.M.; Gutekunst, C.A.; Gearing, M.; Trojanowski, J.Q.; Anderson, M.; Chu, C.T.; Peng, J.; Greenamyre, J.T. A novel transferrin/TfR2-mediated mitochondrial iron transport system is disrupted in Parkinson's disease. Neurobiol. Dis., 2009, 34(3), 417-431.

[50] Adimora, N.J.; Jones, D.P.; Kemp, M.L. A model of redox kinetics implicates the thiol proteome in cellular hydrogen peroxide responses. Antioxid. Redox Signal., 2010, 13(6), 731-743.

[51] Kemp, M.; Go, Y.M.; Jones, D.P. Nonequilibrium thermodynamics of thiol/disulfide redox systems: a perspective on redox systems biology. Free Radic. Biol. Med., 2008, 44(6), 921-937.

[52] Yang, W.; Tiffany-Castiglioni, E. The bipyridyl herbicide paraquat produces oxidative stress-mediated toxicity in human neuroblastoma SH-SY5Y cells: relevance to the dopaminergic pathogenesis. J. Toxicol. Environ. Health A, 2005, 68(22), 19391961.

[53] Sherer, T.B.; Betarbet, R.; Testa, C.M.; Seo, B.B.; Richardson, J.R.; Kim, J.H.; Miller, G.W.; Yagi, T.; Matsuno-Yagi, A.; Greenamyre, J.T. Mechanism of toxicity in rotenone models of Parkinson's disease. J. Neurosci., 2003, 23(34), 10756-10764.

[54] Hawkins, C.L.; Davies, M.J. Generation and propagation of radical reactions on proteins. Biochim. Biophys. Acta, 2001, 1504(2-3), 196-219.

[55] Stadtman, E.R.; Berlett, B.S. Reactive oxygen-mediated protein oxidation in aging and disease. Chem. Res. Toxicol., 1997, 10(5), 485-494.
[56] Stadtman, E.R.; Oliver, C.N. Metal-catalyzed oxidation of proteins. Physiological consequences. J. Biol. Chem., 1991, 266(4), 20052008.

[57] He, Y.; Imam, S.Z.; Dong, Z.; Jankovic, J.; Ali, S.F.; Appel, S.H.; Le, W. Role of nitric oxide in rotenone-induced nigro-striatal injury. J. Neurochem., 2003, 86(6), 1338-1345.

[58] Haavik, J.; Flatmark, T. Isolation and characterization of tetrahydropterin oxidation products generated in the tyrosine 3monooxygenase (tyrosine hydroxylase) reaction. Eur. J. Biochem., 1987, 168(1), 21-26.

[59] Ramsey, A.J.; Fitzpatrick, P.F. Effects of phosphorylation of serine 40 of tyrosine hydroxylase on binding of catecholamines: evidence for a novel regulatory mechanism. Biochemistry, 1998, 37(25), 8980-8986.

[60] Ramsey, A.J.; Fitzpatrick, P.F. Effects of phosphorylation on binding of catecholamines to tyrosine hydroxylase: specificity and thermodynamics. Biochemistry, 2000, 39(4), 773-778.

[61] Barbosa, E.R.; Comerlatti, L.R.; Haddad, M.S.; Scaff, M. [Parkinsonism secondary to ethylene oxide exposure: case report. Arq. Neuropsiquiatr., 1992, 50(4), 531-533.

[62] Muller-Vahl, K.R.; Kolbe, H.; Dengler, R. Transient severe parkinsonism after acute organophosphate poisoning. J. Neurol. Neurosurg. Psychiatry, 1999, 66(2), 253-254.

[63] De La Cruz, C.P.; Revilla, E.; Venero, J.L.; Ayala, A.; Cano, J.; Machado, A. Oxidative inactivation of tyrosine hydroxylase in substantia nigra of aged rat. Free Radic. Biol. Med., 1996, 20(1), 53-61.

[64] Wallace, D.C. Bioenergetic Origins of Complexity and Disease. Cold Spring Harb. Symp. Quant. Biol., 2011, [Epub ahead of print].

[65] Borges, C.R.; Geddes, T.; Watson, J.T.; Kuhn, D.M. Dopamine biosynthesis is regulated by S-glutathionylation. Potential mechanism of tyrosine hydroxylast inhibition during oxidative stress. J. Biol. Chem., 2002, 277(50), 48295-48302.

[66] Park, S.; Geddes, T.J.; Javitch, J.A.; Kuhn, D.M. Dopamine prevents nitration of tyrosine hydroxylase by peroxynitrite and nitrogen dioxide: is nitrotyrosine formation an early step in dopamine neuronal damage? J. Biol. Chem., 2003, 278(31), 2873628742.

[67] Klatt, P.; Lamas, S. Regulation of protein function by Sglutathiolation in response to oxidative and nitrosative stress. Eur. J. Biochem., 2000, 267(16), 4928-4944.

[68] Kuhn, D.M.; Geddes, T.J. Tetrahydrobiopterin prevents nitration of tyrosine hydroxylase by peroxynitrite and nitrogen dioxide. Mol. Pharmacol., 2003, 64(4), 946-953.

[69] Kuhn, D.M.; Geddes, T.J. Reduced nicotinamide nucleotides prevent nitration of tyrosine hydroxylase by peroxynitrite. Brain Res., 2002, 933(1), 85-89.

[70] Kuhn, D.M.; Sakowski, S.A.; Sadidi, M.; Geddes, T.J. Nitrotyrosine as a marker for peroxynitrite-induced neurotoxicity: the beginning or the end of the end of dopamine neurons? $J$. Neurochem., 2004, 89(3), 529-536.

[71] Franco, J.L.; Posser, T.; Gordon, S.L.; Bobrovskaya, L.; Schneider, J.J.; Farina, M.; Dafre, A.L.; Dickson, P.W.; Dunkley, P.R. Expression of tyrosine hydroxylase increases the resistance of human neuroblastoma cells to oxidative insults. Toxicol. Sci., 2009, 113(1), 150-157.

[72] Kaushik, P.; Gorin, F.; Vali, S. Dynamics of tyrosine hydroxylase mediated regulation of dopamine synthesis. J. Comput. Neurosci., 2007, 22(2), 147-160.

[73] Moy, L.Y.; Tsai, L.H. Cyclin-dependent kinase 5 phosphorylates serine 31 of tyrosine hydroxylase and regulates its stability. J. Biol. Chem., 2004, 279(52), 54487-54493.

[74] Iida, Y.; Sawabe, K.; Kojima, M.; Oguro, K.; Nakanishi, N.; Hasegawa, H. Proteasome-driven turnover of tryptophan hydroxylase is triggered by phosphorylation in RBL2H3 cells, a serotonin producing mast cell line. Eur. J. Biochem., 2002, 269(19), 4780-4788.

[75] Kawahata, I.; Tokuoka, H.; Parvez, H.; Ichinose, H. Accumulation of phosphorylated tyrosine hydroxylase into insoluble protein aggregates by inhibition of an ubiquitin-proteasome system in PC12D cells. J. Neural Transm., 2009, 116(12), 1571-1578.

[76] Winterbourn, C.C.; Hampton, M.B. Thiol chemistry and specificity in redox signaling. Free Radic. Biol. Med., 2008, 45(5), 549-561.

[77] McCubrey, J.A.; Franklin, R.A. Reactive oxygen intermediates and signaling through kinase pathways. Antioxid. Redox Signal., 2006, $8(9-10), 1745-1748$. 
[78] Agnati, L.F.; Fuxe, K.; Benfenati, F.; Zini, I.; Zoli, M.; Fabbri, L.; Harfstrand, A. Computer-assisted morphometry and microdensitometry of transmitter- identified neurons with special reference to the mesostriatal dopamine pathway. Methodological aspects. Acta Physiol. Scand. Suppl., 1984, 532, 5-36.

[79] Finch, C.E.; Morgan, D.G. RNA and protein metabolism in the aging brain. Ann. Rev. Neurosci., 1990, 13, 75-88.

[80] Venero, J.L.; Machado, A.; Cano, J. Changes in monoamines and their metabolite levels in substantia nigra of aged rats. Mech. Ageing Dev., 1989, 49(3), 227-233.

[81] Venero, J.L.; Machado, A.; Cano, J. Age effects on monoamine turnover of the rat substantia nigra. Brain Res., 1991, 557(1-2), 109-114.

[82] McGeer, P.L.; Itagaki, S.; Akiyama, H.; McGeer, E.G. Rate of cell death in parkinsonism indicates active neuropathological process. Ann. Neurol., 1988, 24(4), 574-576.

[83] McGeer, P.L.; McGeer, E.G.; Suzuki, J.S. Aging and extrapyramidal function. Arch. Neurol., 1977, 34(1), 33-35.

[84] Allen, E.; Carlson, K.M.; Zigmond, M.J.; Cavanaugh, J.E. LDOPA reverses motor deficits associated with normal aging in mice. Neurosci. Lett., 2010, 489(1), 1-4.

[85] Anandhan, A.; Tamilselvam, K.; Radhiga, T.; Rao, S.; Essa, M.M.; Manivasagam, T. Theaflavin, a black tea polyphenol, protects nigral dopaminergic neurons against chronic MPTP/probenecid induced Parkinson's disease. Brain Res., 2011, 1433, 104-113.

[86] Ahmad, S.; Khan, M.B.; Hoda, M.N.; Bhatia, K.; Haque, R.; Fazili, I.S.; Jamal, A.; Khan, J.S.; Katare, D.P. Neuroprotective Effect of Sesame Seed Oil in 6-Hydroxydopamine Induced Neurotoxicity in Mice Model: Cellular, Biochemical and Neurochemical Evidence. Neurochem. Res., 2011, 37(3), 516-526.

[87] Huh, S.H.; Chung, Y.C.; Piao, Y.; Jin, M.Y.; Son, H.J.; Yoon, N.S.; Hong, J.Y.; Pak, Y.K.; Kim, Y.S.; Hong, J.K.; Hwang, O.; Jin, B.K. Ethyl pyruvate rescues nigrostriatal dopaminergic neurons by regulating glial activation in a mouse model of Parkinson's disease. J. Immunol., 2011, 187(2), 960-969.

[88] Sai, Y.; Wu, Q.; Le, W.; Ye, F.; Li, Y.; Dong, Z. Rotenone-induced PC12 cell toxicity is caused by oxidative stress resulting from altered dopamine metabolism. Toxicol. In Vitro, 2008, 22(6), 14611468.

[89] Kim, Y.H.; Rane, A.; Lussier, S.; Andersen, J.K. Lithium protects against oxidative stress-mediated cell death in alpha-synucleinoverexpressing in vitro and in vivo models of Parkinson's disease. J. Neurosci. Res., 2011, 89(10), 1666-1675.

[90] Banerjee, U.; Dasgupta, A.; Rout, J.K.; Singh, O.P. Effects of lithium therapy on $\mathrm{Na}(+)-\mathrm{K}(+)$-ATPase activity and lipid peroxidation in bipolar disorder. Prog. Neuropsychopharmacol. Biol. Psychiatry, 2012, 37(1), 56-61.

[91] Tan, H.; Young, L.T.; Shao, L.; Che, Y.; Honer, W.G.; Wang, J.F. Mood stabilizer lithium inhibits amphetamine-increased 4hydroxynonenal-protein adducts in rat frontal cortex. Int. J. Neuropsychopharmacol., 2011, [Epub ahead of print]

[92] Brandish, P.E.; Su, M.; Holder, D.J.; Hodor, P.; Szumiloski, J.; Kleinhanz, R.R.; Forbes, J.E.; McWhorter, M.E.; Duenwald, S.J.; Parrish, M.L.; Na, S.; Liu, Y.; Phillips, R.L.; Renger, J.J.; Sankaranarayanan, S.; Simon, A.J.; Scolnick, E.M. Regulation of gene expression by lithium and depletion of inositol in slices of adult rat cortex. Neuron, 2005, 45(6), 861-872.

[93] Willing, A.E.; Zigova, T.; Milliken, M.; Poulos, S.; Saporta, S.; McGrogan, M.; Snable, G.; Sanberg, P.R. Lithium exposure enhances survival of NT2N cells(hNT neurons) in the hemiparkinsonian rat. Eur. J. Neurosci., 2002, 16(12), 2271-2278.

[94] Ferrie, L.; Young, A.H.; McQuade, R. Effect of lithium and lithium withdrawal on potassium-evoked dopamine release and tyrosine hydroxylase expression in the rat. Int. J. Neuropsychopharmacol., 2006, 9(6), 729-735.

[95] Takeda, A. Movement of zinc and its functional significance in the brain. Brain Res. Brain Res. Rev., 2000, 34(3), 137-148.

[96] Kumar, A.; Ahmad, I.; Shukla, S.; Singh, B.K.; Patel, D.K.; Pandey, H.P.; Singh, C. Effect of zinc and paraquat co-exposure on neurodegeneration: Modulation of oxidative stress and expression of metallothioneins, toxicant responsive and transporter genes in rats. Free Radic. Res., 2010, 44(8), 950-965.

[97] Kumar, A.; Singh, B.K.; Ahmad, I.; Shukla, S.; Patel, D.K.; Srivastava, G.; Kumar, V.; Pandey, H.P.; Singh, C. Involvement of $\mathrm{NADPH}$ oxidase and glutathione in zinc-induced dopaminergic neurodegeneration in rats: Similarity with paraquat neurotoxicity. Brain Res., 2011, 1438, 48-64.

[98] Dexter, D.T.; Carayon, A.; Javoy-Agid, F.; Agid, Y.; Wells, F.R.; Daniel, S.E.; Lees, A.J.; Jenner, P.; Marsden, C.D. Alterations in the levels of iron, ferritin and other trace metals in Parkinson's disease and other neurodegenerative diseases affecting the basal ganglia. Brain, 1991, 114(Pt 4), 1953-1975.

[99] Lin, A.M.; Fan, S.F.; Yang, D.M.; Hsu, L.L.; Yang, C.H. Zincinduced apoptosis in substantia nigra of rat brain: neuroprotection by vitamin D3. Free Radic. Biol. Med., 2003, 34(11), 1416-1425.

[100] Webster, K.A.; Discher, D.J.; Bishopric, N.H. Induction and nuclear accumulation of fos and jun proto-oncogenes in hypoxic cardiac myocytes. J. Biol. Chem., 1993, 268(22), 16852-16858.

[101] Bauskin, A.R.; Alkalay, I.; Ben-Neriah, Y. Redox regulation of a protein tyrosine kinase in the endoplasmic reticulum. Cell, 1991, 66(4), 685-696.

[102] Cowan, D.B.; Weisel, R.D.; Williams, W.G.; Mickle, D.A. The regulation of glutathione peroxidase gene expression by oxygen tension in cultured human cardiomyocytes. J. Mol. Cell Cardiol., 1992, 24(4), 423-433.

[103] Wang, G.L.; Semenza, G.L. General involvement of hypoxiainducible factor 1 in transcriptional response to hypoxia. Proc. Natl. Acad. Sci. USA, 1993, 90(9), 4304-4308.

[104] Rhodes, D.; Klug, A. Zinc fingers. Sci. Am., 1993, 268(2), 56-59.

[105] Berg, J.M. Sp1 and the subfamily of zinc finger proteins with guanine-rich binding sites. Proc. Natl. Acad. Sci. USA, 1992, 89(23), 11109-11110.

[106] Desjarlais, J.R.; Berg, J.M. Toward rules relating zinc finger protein sequences and DNA binding site preferences. Proc. Natl. Acad. Sci. USA, 1992, 89(16), 7345-7349.

[107] Kadonaga, J.T.; Carner, K.R.; Masiarz, F.R.; Tjian, R. Isolation of cDNA encoding transcription factor Sp1 and functional analysis of the DNA binding domain. Cell, 1987, 51(6), 1079-1090.

[108] Gill, G.; Pascal, E.; Tseng, Z.H.; Tjian, R. A glutamine-rich hydrophobic patch in transcription factor $\mathrm{Sp} 1$ contacts the dTAFII110 component of the Drosophila TFIID complex and mediates transcriptional activation. Proc. Natl. Acad. Sci. USA, 1994, 91(1), 192-196.

[109] Kim, S.J.; Onwuta, U.S.; Lee, Y.I.; Li, R.; Botchan, M.R.; Robbins, P.D. The retinoblastoma gene product regulates Sp1-mediated transcription. Mol. Cell Biol., 1992, 12(6), 2455-2463.

[110] Kingsley, C.; Winoto, A. Cloning of GT box-binding proteins: a novel Sp1 multigene family regulating $\mathrm{T}$-cell receptor gene expression. Mol. Cell. Biol., 1992, 12(10), 4251-4261.

[111] Ammendola, R.; Mesuraca, M.; Russo, T.; Cimino, F. The DNAbinding efficiency of $\mathrm{Sp} 1$ is affected by redox changes. Eur. $J$. Biochem., 1994, 225(1), 483-489.

[112] Hentze, M.W.; Rouault, T.A.; Harford, J.B.; Klausner, R.D. Oxidation-reduction and the molecular mechanism of a regulatory RNA-protein interaction. Science, 1989, 244(4902), 357-359.

[113] Pognonec, P.; Kato, H.; Roeder, R.G. The helix-loop-helix/leucine repeat transcription factor USF can be functionally regulated in a redox-dependent manner. J. Biol. Chem., 1992, 267(34), 2456324567.

[114] Cookson, M.R. Pathways to Parkinsonism. Neuron, 2003, 37(1), 710.

[115] Bonifati, V.; Rizzu, P.; van Baren, M.J.; Schaap, O.; Breedveld, G.J.; Krieger, E.; Dekker, M.C.; Squitieri, F.; Ibanez, P.; Joosse, M.; van Dongen, J.W.; Vanacore, N.; van Swieten, J.C.; Brice, A.; Meco, G.; van Duijn, C.M.; Oostra, B.A.; Heutink, P. Mutations in the DJ-1 gene associated with autosomal recessive early-onset parkinsonism. Science, 2003, 299(5604), 256-259.

[116] Annesi, G.; Savettieri, G.; Pugliese, P.; D'Amelio, M.; Tarantino, P.; Ragonese, P.; La Bella, V.; Piccoli, T.; Civitelli, D.; Annesi, F.; Fierro, B.; Piccoli, F.; Arabia, G.; Caracciolo, M.; Ciro Candiano, I.C.; Quattrone, A. DJ-1 mutations and parkinsonism-dementiaamyotrophic lateral sclerosis complex. Ann. Neurol., 2005, 58(5), 803-807.

[117] Abou-Sleiman, P.M.; Healy, D.G.; Quinn, N.; Lees, A.J.; Wood, N.W. The role of pathogenic DJ-1 mutations in Parkinson's disease. Ann. Neurol., 2003, 54(3), 283-286.

[118] Miller, D.W.; Ahmad, R.; Hague, S.; Baptista, M.J.; Canet-Aviles, R.; McLendon, C.; Carter, D.M.; Zhu, P.P.; Stadler, J.; Chandran, J.; Klinefelter, G.R.; Blackstone, C.; Cookson, M.R. L166P mutant DJ-1, causative for recessive Parkinson's disease, is degraded 
through the ubiquitin-proteasome system. J. Biol. Chem., 2003, 278(38), 36588-36595.

[119] Reddy, S.D.; Rayala, S.K.; Ohshiro, K.; Pakala, S.B.; Kobori, N.; Dash, P.; Yun, S.; Qin, J.; O'Malley, B.W.; Kumar, R. Multiple coregulatory control of tyrosine hydroxylase gene transcription. Proc. Natl. Acad. Sci. USA, 2011, 108(10), 4200-4205.

[120] Taira, T.; Saito, Y.; Niki, T.; Iguchi-Ariga, S.M.; Takahashi, K.; Ariga, H. DJ-1 has a role in antioxidative stress to prevent cell death. EMBO Rep., 2004, 5(2), 213-218.

[121] Yanagida, T.; Kitamura, Y.; Yamane, K.; Takahashi, K.; Takata, K.; Yanagisawa, D.; Yasui, H.; Taniguchi, T.; Taira, T.; Honda, T.; Ariga, H. Protection against oxidative stress-induced neurodegeneration by a modulator for DJ-1, the wild-type of familial Parkinson's disease-linked PARK7. J. Pharmacol. Sci., 2009, 109(3), 463-468.

[122] Yanagida, T.; Tsushima, J.; Kitamura, Y.; Yanagisawa, D.; Takata, K.; Shibaike, T.; Yamamoto, A.; Taniguchi, T.; Yasui, H.; Taira, T.; Morikawa, S.; Inubushi, T.; Tooyama, I.; Ariga, H. Oxidative stress induction of DJ-1 protein in reactive astrocytes scavenges free radicals and reduces cell injury. Oxid. Med. Cell Longev., 2009, 2(1), 36-42.

[123] Zhong, N.; Kim, C.Y.; Rizzu, P.; Geula, C.; Porter, D.R.; Pothos, E.N.; Squitieri, F.; Heutink, P.; Xu, J. DJ-1 transcriptionally upregulates the human tyrosine hydroxylase by inhibiting the sumoylation of pyrimidine tract-binding protein-associated splicing factor. J. Biol. Chem., 2006, 281(30), 20940-20948. 